\title{
Ocupação irregular em áreas de recarga do Aquífero Guarani e vegetação ripária em Lages-SC
}

\author{
Marcelo Mazzolli* \\ Natalia Carolina Moraes Ehrhardt-Brocardo**
}

\section{Resumo}

O Aquífero Guarani constitui uma significativa reserva de água subterrânea da América do Sul. No município de Lages, uma extensão considerável das áreas de recarga do Arenito Botucatu, que constitui o Aquífero, está sob ocupação urbana. Observou-se a existência de ocupação urbana sobre ou próximo às áreas de recarga, ocupação irregular e abertura de rua em área de vegetação ripária protegida (Área de Proteção Permanente), e efluentes domésticos lançados diretamente em corpos d'água. Este estudo indica que a legislação ambiental está sendo abertamente desconsiderada na área de estudo, mesmo pela gestão municipal. Considerando ser este um estudo de caso, não é de todo improvável que o mesmo problema ocorra em outras áreas urbanas e suburbanas do país.

Palavras-chave: Águas subterrâneas; Vulnerabilidade ambiental; Uso do Solo.

Irregular occupation in areas of recharge of Aquifer Guarani and riparian vegetation, Lages-SC

* Universidade do Planalto Catarinense (UNIPLAC) Biólogo, Doutor em Ecologia Programa de Pós Graduação em Ambiente e Saúde (PPGAS). Especialização em Desenvolvimento Sustentável e Manejo Ambiental (marcelo puma@yahoo.com).

** Universidade do Planalto Catarinense (UNIPLAC) Bióloga, Mestre em Manejo do Solo. Especialização em Desenvolvimento Sustentável e Manejo Ambiental (biosapos@gmail.com).

Geosul, Florianópolis, v. 28, n. 55, p 163-180, jan./jun. 2013 
MAZZOLLI, M. Ocupação irregular em áreas de recarga do Aquífero ...

\section{Abstract}

The Guarani Aquifer is a significant groundwater reserve in South America. In the city of Lages, a considerable extension of recharge areas of the Botucatu Sandstone, that make up the Aquifer, is under urban occupation. We observed the presence of human occupation on or near the recharge areas, irregular occupation and building of a road in protected areas of riparian vegetation (Areas of Pemanent Protection), and domestic effluents dumped directly into waterbodies. This study points out that the environmental legislation is being openly desconsidered, even by the local government. Considering the results as a study case, it is not at all unlikely that the same issues may be occurring in other urban and suburban areas of the country.

Key words: Groundwater; Environmental Vulnerability; Land Use.

\section{Introdução}

O aquífero é uma formação geológica do subsolo, constituída por rochas permeáveis, que possibilita o armazenamento de água em seus poros ou fraturas, sendo o material geológico capaz de servir de depositório e de transmissor da água armazenada (BORGHETTI et al., 2004). O Aquífero Guarani compreende uma área aproximada de 1,2 milhões de $\mathrm{km}^{2}$, estendendo-se pelo Brasil, Paraguai, Uruguai e Argentina. No estado de Santa Catarina, o Aquífero Guarani ocupa 51,6\% da área total do estado.

O Arenito Botucatu, que constitui o Aquífero Guarani, foi formado por meio da deposição e compactação de camadas de areia em ambiente desértico na Bacia Geológica Sedimentar do Paraná durante a Era Mesozóica. Após este evento, um intenso vulcanismo fissural tornou o Aquífero Guarani parcialmente confinado e protegido sob rocha basáltica. Desta forma, o Aquífero 
MAZZOLLI, M. Ocupação irregular em áreas de recarga do Aquífero ...

Guarani possui áreas confinadas e áreas livres - os afloramentos, que devido ao seu contato com a superfície, e pelo fato de serem porosos e permeáveis, encontram-se vulneráveis à contaminação superficial.

O município de Lages, localizado na Região do Planalto Serrano Catarinense (ou simplesmente Região Serrana), está inserido na Bacia Geológica Sedimentar do Paraná, constituída por rochas sedimentares, dentre elas, arenitos, folhelhos e siltitos. Estima-se que há 180 milhões de anos, iniciou-se um processo de vulcanismo, com a abertura de fendas nas camadas superiores da Terra, cobrindo a área da Bacia do Paraná com a lava extravasada (basalto). Em um período posterior, a Bacia do Paraná sofreu um processo de soerguimento e erosão parcial, deixando à mostra as várias camadas das rochas sedimentares situadas sob as rochas vulcânicas (SEPLAN, 2008). De acordo com Scheibe e Hirata (2008), os limites das áreas de afloramento das rochas vulcânicas da Serra Geral e dos arenitos da Formação Botucatu em Santa Catarina estariam, por sua vez, diretamente relacionados a uma série de lineamentos tectônicos de grande expressão, sendo a endentação ocasionada pela sobre-elevação do Domo de Lages uma das principais evidências da tectônica de blocos.

As principais fontes poluidoras da Região Serrana são os esgotos urbanos, os despejos industriais e o assoreamento, resultado do desmatamento e do manejo inadequado do solo (SECRETARIA DE ESTADO E DESENVOLVIMENTO URBANO E MEIO AMBIENTE, 1997).

Apesar do arcabouço de leis ambientais brasileiras, a ocupação humana em áreas protegidas é crescente (e.g. SÁNCHEZ, 2003; JÚNIOR, 2003). Entre as leis brasileiras, destacam-se as leis federais 12.727 e 12.651, do ano de 2012, que atualizam o Código Florestal, e ainda a Resolução 302/02 do CONAMA. Nestas, as áreas declivosas e com cobertura vegetal ripária são consideradas especialmente vulneráveis. Seguindo critérios de vulnerabilidade, podem enquadrar-se como Áreas de Preservação Permanente (APP). A APP é toda área protegida 
MAZZOLLI, M. Ocupação irregular em áreas de recarga do Aquífero ...

coberta ou não por vegetação nativa, com a função ambiental de preservar os recursos hídricos, a paisagem, a estabilidade geológica, a biodiversidade, o fluxo gênico da fauna e flora, proteger o solo e assegurar o bem-estar das populações humanas (artigo $3^{\circ}$ da Lei 12.651/2012). Áreas vulneráveis compreendidas nos perímetros urbanos, nas regiões metropolitanas e nas aglomerações urbanas seguem os planos diretores de cada município, cuja exigência não deve ser menor do que a lei federal. São consideradas faixas de APP de vegetação ripária 30 metros para cada lado ao longo de margens de cursos de água com menos de dez metros de largura, exceto para casos excepcionais definidos em lei.

A lei ambiental catarinense $n^{\circ} 14.675$, sancionada em abril de 2009, contraria a faixa mínima de APP estabelecida na lei federal, mas dá outras provisões para a proteção da qualidade da água superficial e subterrânea. Proíbe o lançamento, direto ou indireto, em corpos de água, de qualquer resíduo sólido, bem como, a diluição de efluentes de uma fonte poluidora para fins de atendimento a padrões de lançamento final em corpos de água. Estabelece que a implantação de loteamentos e outros empreendimentos que impliquem na utilização de águas subterrâneas ou ainda na impermeabilização de significativas porções de terreno, devem ser feita de forma a preservar o ciclo hidrológico original. E no caso de aquíferos em condições críticas, compete ao órgão ambiental estadual (Fundação do Meio Ambiente - FATMA) estabelecer restrições ambientais visando, no mínimo, não acentuar o comprometimento da disponibilidade hídrica em quantidade ou qualidade, cabendo ao órgão gestor dos recursos hídricos estabelecer medidas de recuperação. Nas ocupações em área de ocorrência de aquífero poroso, como o Aquífero Guarani, a lei catarinense exige o tratamento do esgoto.

Face à ocupação irregular de áreas de interesse ambiental, a gestão municipal parece incapaz do estabelecimento de uma ordenação (e.g. LIMA, 2001). Em outras situações, o poder público pode atuar como incentivador da ocupação ambiental irregular, 
MAZZOLLI, M. Ocupação irregular em áreas de recarga do Aquífero ...

como verificado há duas décadas em Roraima (BARBOSA, 1993), com situações em menor escala talvez passando imperceptíveis aos órgãos fiscalizadores.

Muitas pesquisas sobre o tema são descritivas, apenas detalhando o fato consumado. No caso da ocupação irregular em APPs, criadora de um grande passivo ambiental, não basta descrever a situação. Pesquisas precisam objetivar de forma prática reconhecer os fatores e atores envolvidos no processo, para que as fontes de irregularidade sejam localizadas e reparadas.

Este é um estudo de caso sobre a expansão urbana irregular, realizado no município de Lages, em área de recarga do Aquífero Guarani e em Áreas de Preservação Permanente (APP). Procurouse descrever a situação atual, e também acompanhar o progresso no estabelecimento de residências e obras irregulares durante $\mathrm{o}$ período de estudo.

\section{Material e Métodos}

O município de Lages está localizado no planalto sul do Estado de Santa Catarina, possui uma extensão territorial de $2.651,4 \mathrm{~km}^{2}$ e altitude aproximada de 916 metros.

O município de Lages tem seu território inteiramente inserido na Região Hidrográfica (RH) 4 - Planalto de Lages, que é a maior Região Hidrográfica em extensão do Estado de Santa Catarina com $22.787 \mathrm{~km}^{2}$, constituída pelas bacias hidrográficas do Rio Canoas, que corresponde à maior bacia hidrográfica estadual $\left(15.510 \mathrm{~km}^{2}\right)$ e do Rio Pelotas $\left(7.277 \mathrm{~km}^{2}\right)$. Os corpos d'água que cortam o seu território são o Rio Carahá, Rio Caveiras, Rio Lava Tudo, Rio Pelotinhas, Rio Pelotas e Rio Canoas (SDS, 2006).

A área de estudo tem como ponto central o Bairro Santa Helena, delimitada ao norte pela Rua Mateus Junqueira, ao sul pela Avenida Santa Catarina, ao leste pela Avenida Caldas Júnior e a oeste pela BR 116. No contexto do perímetro urbano de Lages, o bairro Santa Helena situa-se em uma área periférica a sudoeste, 
MAZZOLLI, M. Ocupação irregular em áreas de recarga do Aquífero ...

com áreas naturais modificadas, mas ainda não inteiramente ocupadas por residências.

A primeira etapa do trabalho consistiu no diagnóstico do uso e ocupação da terra nesta área delimitada. Realizou-se a identificação e o mapeamento do uso da terra por meio da classificação supervisionada dos atributos da paisagem no laboratório de Ecologia da Universidade do Planalto Catarinense. As áreas foram delimitadas por polígonos desenhados sobre os diferentes usos da terra sobre imagens utilizando o programa Google Earth ${ }^{1}$. As formas de ocupação do solo foram diferenciadas e identificadas em seis categorias de usos da terra representadas por coberturas vegetais (vegetação natural, campos naturais, vegetação exótica) e áreas urbanizadas (habitação individual, quadras, empresas). Os polígonos e linhas foram em seguida exportados para o TrackMaker Pro ${ }^{\circledR}$ (Geo Studio Tech, MG) onde o arquivo foi guardado em formato Shape, compatível com o ArcView 3.2 (ESRI, NY), a partir do qual foi possível utilizar o Xtools (Dept. of Forestry, Oregon) para calcular a área dos polígonos e portanto a extensão da área de ocupação de cada uma das formas de uso do solo.

Foram registrados alguns pontos de afloramento do arenito Botucatu ao redor de uma das nascentes do Rio Carahá, o córrego Bela Vista (segundo mapa em CAD da SEPLAN municipal), cuja ocupação irregular foi caracterizada.

Adotou-se o termo 'vegetação ripária' como termo geral para definir a área em torno de corpos d'água, em razão da diversidade de nomenclaturas existentes para definir esta área, muitas vezes com significado muito restrito quanto a sua amplitude (KOBIYAMA, 2003). O conceito de Área de Preservação Permanente (APP), de natureza legal, foi aplicado quando apropriado.

\section{Resultados}

${ }^{1}$ Google Earth é marca registrada da Google, Inc. 
MAZZOLLI, M. Ocupação irregular em áreas de recarga do Aquífero ...

Por meio da classificação supervisionada, observou-se que o uso da terra na área delimitada no estudo caracteriza-se pela predominância de campos naturais, seguido de floresta em estágio inicial e secundário de regeneração. $O$ plantio de exóticas, sobretudo o Pinus sp., apresenta distribuição no entorno das áreas urbanizadas, substituindo os campos naturais. As áreas urbanizadas (habitação individual, quadras, empresas), ainda que correspondam a um quarto da área (Tabela 1), estão presentes sobre ou próximas às áreas de recarga do Aquífero Guarani (Figuras 1 e 2).

Tabela 01: Uso da terra no bairro Santa Helena, município de Lages.

\begin{tabular}{l|l|rr}
\hline \multicolumn{2}{c|}{ Uso da Terra } & \multicolumn{1}{c}{ ha } & \multicolumn{1}{c}{$\%$} \\
\hline \multirow{4}{*}{ Coberturas Vegetais } & Floresta nativa & 99,90 & 13,25 \\
\cline { 2 - 2 } & Campos naturais & 408,49 & 54,18 \\
\cline { 2 - 2 } & Floresta exótica & 62,00 & 8,22 \\
\multirow{4}{*}{ Áreas Urbanizadas } & Habitação Individual & 6,84 & 0,91 \\
\cline { 2 - 2 } & Quadras & 91,85 & 12,18 \\
\cline { 2 - 3 } & Empresas & 84,92 & 11,26 \\
\hline \multicolumn{2}{c}{ Total } & 754,00 \\
\hline
\end{tabular}

Observou-se que parte da APP das nascentes do Rio Carahá encontra-se ocupada por casas que lançam seus efluentes diretamente nos corpos d'água. Diagnosticou-se parcial ou total impermeabilização da rocha porosa e potencial de contaminação de lençóis subterrâneos por águas servidas. Embora tenha havido um planejamento habitacional para nesta área, ordenado em loteamentos (em quadras na Figura 1), fica evidenciado o avanço da ocupação irregular das margens pela instalação de residências individuais (Figuras 1 e 2). A ocupação em áreas não planejadas sobre a APP indica que a forma de uso e ocupação deste solo é a principal fonte de poluição hídrica. 
MAZZOLLI, M. Ocupação irregular em áreas de recarga do Aquífero ...

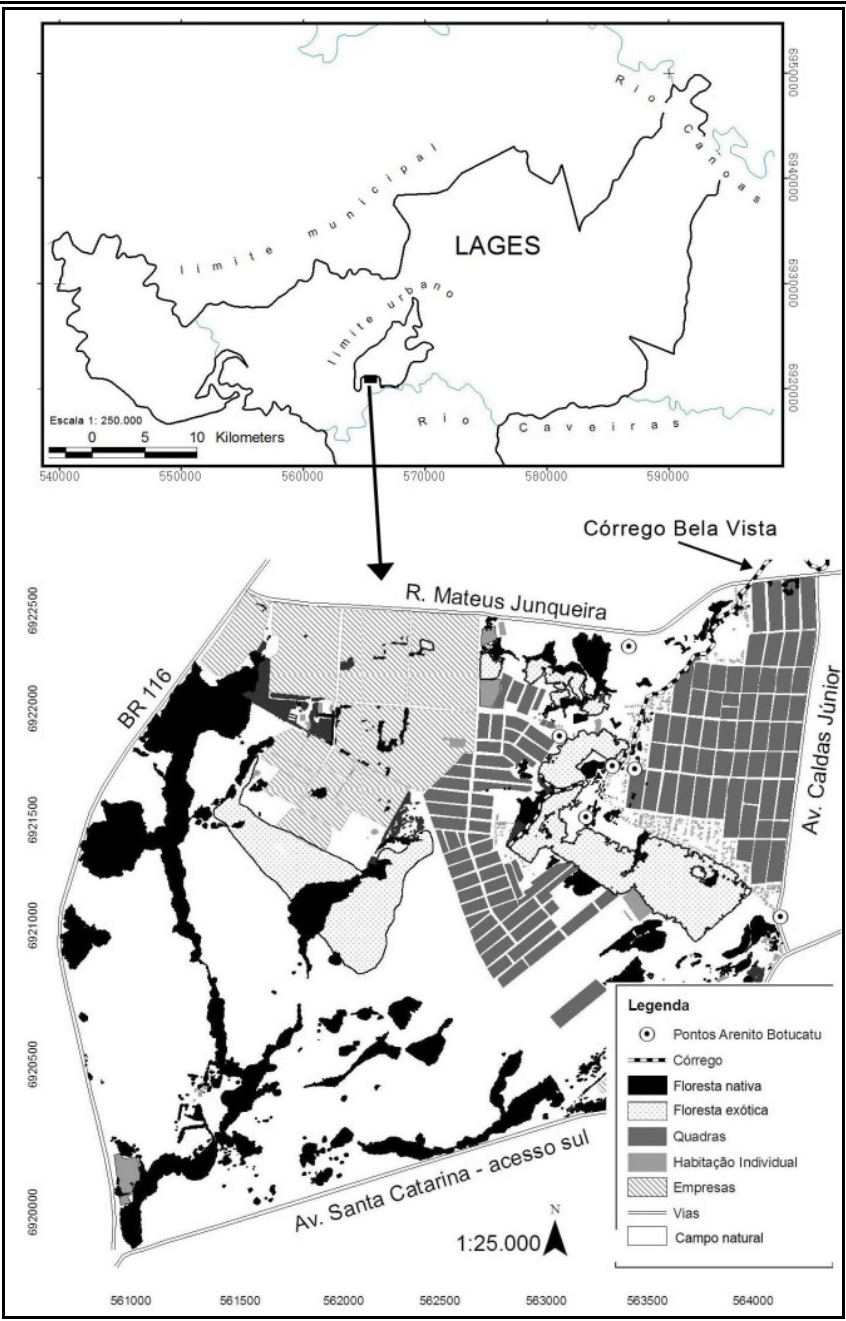

Figura 1: Classificação do uso da terra no bairro Santa Helena e entorno, com caracterização de um corpo hídrico em área de afloramento do Arenito Botucatu nos pontos identificados, mas não restrito a eles. O Arenito Botucatu é praticamente contínuo na direção sul até o Rio Caveiras (Bairro Sta Catarina). 
MAZZOLLI, M. Ocupação irregular em áreas de recarga do Aquífero ...

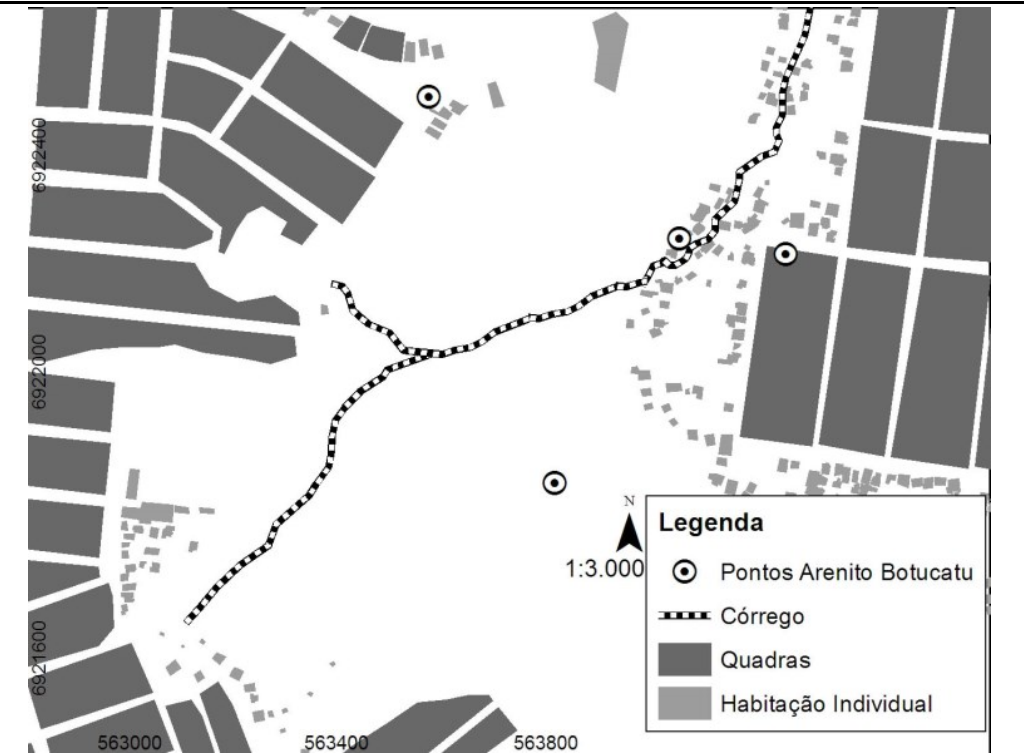

Figura 2: Ampliação da figura anterior destacando as nascentes do córrego Bela Vista com as habitações individuais não planejadas, muitas justapostas ou a menos de 30 metros do córrego.

Além da ocupação irregular pela população, constatou-se que o poder público municipal participa ativamente na deterioração da qualidade ambiental da área, em duas circunstâncias. A primeira foi a abertura de rua pública durante o período de execução desta pesquisa, de nome Alberto dos Santos, a uma distância que enquadra-se como dentro da APP, ou seja, a menos de 30 metros de distância, com propósito obscuro, já que conecta dois fins de rua (Figura 3). A segunda foi a constatação de uma estação de tratamento de esgoto localizada acima da nascente do Córrego Bela Vista no qual despeja seus efluentes, uma piscina de decantação subdimensionada, como constatado pelo odor forte e transparência da água do córrego, e estudos anteriores (ver discussão). 
MAZZOLLI, M. Ocupação irregular em áreas de recarga do Aquífero ...

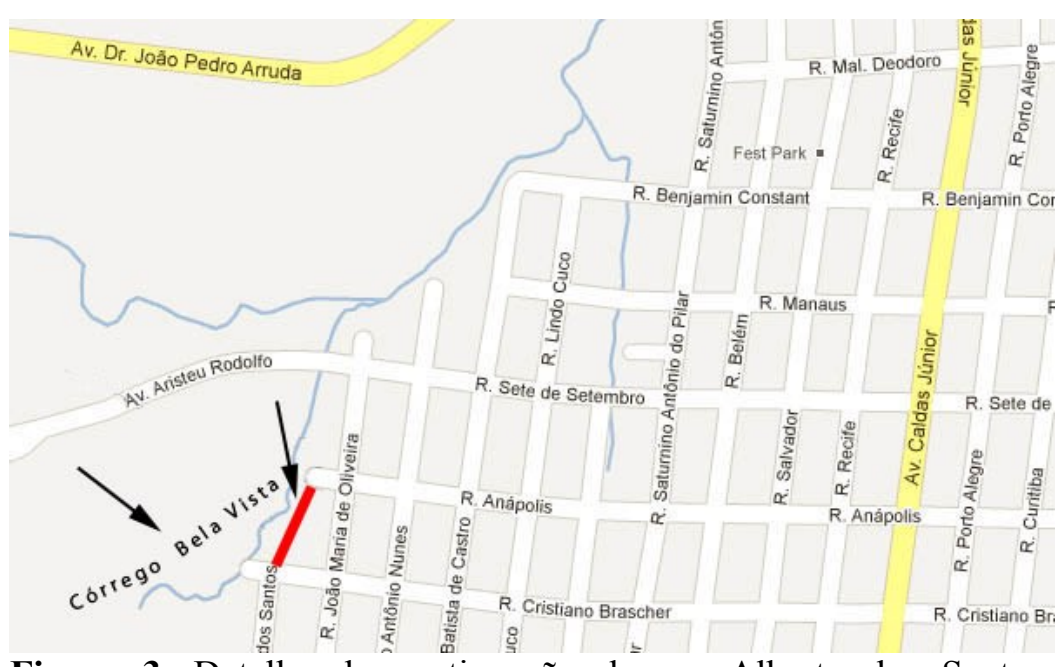

Figura 3. Detalhe da continuação da rua Alberto dos Santos (destaque em vermelho) em área de APP de vegetação ripária.

\section{Discussão}

Em função da existência da exigência legal, constataram-se irregularidades na ocupação do solo decorrentes da expansão urbana na área delimitada no estudo.

As áreas habitadas (quadras e habitações individuais) representam uma fonte de contaminação e impermeabilização nas áreas de afloramento e em uma das nascentes do Rio Carahá (córrego Bela Vista), objetos do levantamento realizado. A potencial contaminação biológica, principalmente coliformes, nestes locais próximos às áreas habitadas, deve-se ao lançamento de dejetos orgânicos e inorgânicos, a criação de animais e ainda ao acúmulo de resíduos (plástico, latas, mobílias), também constatado por Gonçalves et al. (2005). É possível que a contaminação biológica atinja o lençol subterrâneo através da infiltração nas áreas de recarga. A contaminação subterrânea em áreas de recarga 
MAZZOLLI, M. Ocupação irregular em áreas de recarga do Aquífero ...

por ocupação desordenada é pouco documentada no Brasil. Os casos documentados são em situações de abertura de poços (e.g. ARRUDA et al., 2010), depósitos de lixo (e.g. ROCHA e HORBE, 2006), e necrochorume (e.g. ALMEIDA et al., 2006). A literatura internacional, no entanto, mostra que a infiltração através da rocha arenosa é uma realidade (e.g. WHITEHEAD et al., 1999; POWELL et al., 2003).

A redução da infiltração da água no solo para recarga do aquífero, seja pela impermeabilização e/ou compactação (VANZELA et al., 2010) ou pelo aumento do escoamento superficial (SILVA et al., 2005), é um agravante. Lages já vivencia o transtorno e os prejuízos gerados pelo alagamento de bairros e vias principais situadas no entorno do Rio Carahá $^{2}$, do qual o córrego Bela Vista é tributário. O manejo florestal inadequado também pode produzir escoamento superficial, sobretudo no momento da retirada da madeira, deixando o solo descoberto. $\mathrm{Na}$ área de estudo, uma parte da vegetação natural ripária foi substituída pelo plantio de espécies arbóreas exóticas, uma vez que é uma atividade econômica expressiva na região, a qual abriga várias empresas de processamento de madeira e celulose.

Lages carece de uma política para proteção das áreas de recarga do Aquífero Guarani, bem como de suas áreas verdes ou florestadas. A delimitação de 'áreas verdes' ainda consta nos mapas antigos do SEPLAN (Secretaria do Planejamento), mas são apenas seções de quadras, ou seja, não são áreas representativas. Estas áreas foram invadidas e não constam nos mapas atuais digitais (no formato Autocad) de posse da SEPLAN. Aparentemente a Secretaria de Obras e a Secretaria de Saneamento (SEMASA) são desvinculadas de um departamento gestor ambiental, como se depreende, respectivamente, da abertura de uma rua em área de APP e vegetação ripária, e do despejo de esgoto não tratado em uma nascente pela própria SEMASA. Lages

${ }^{2}$ Disponível em: http://www.clmais.com.br/informacao/30475/. Acesso em: $12 / \mathrm{mar} / 2012$. 
MAZZOLLI, M. Ocupação irregular em áreas de recarga do Aquífero ...

vem implementando uma política de saneamento básico, almejando, segundo depoimento de técnicos da secretaria, canalizar e tratar $80 \%$ dos efluentes domésticos da cidade, através do programa criado pela Resolução Federal Saneamento para Todos, $n^{\circ} 476$ de 31/05/2005. Entretanto, o plano não tem levado em consideração áreas prioritárias, como são aquelas que abrigam afloramentos do Arenito Botucatu.

Na lei orgânica municipal de Lages ${ }^{3}$, o artigo 213, parágrafo 2, orienta que o poder público estará incumbido de, entre outras ações ambientais:

r) controlar e fiscalizar obras, atividades, processos produtivos e empreendimentos que, direta ou indiretamente, possam causar degradação ou depredação do meio ambiente, exigindo medidas preventivas ou corretivas e aplicando as sanções administrativas pertinentes;

s) realizar o planejamento e o zoneamento ambientais, considerando as características locais, e articular os respectivos planos, programas e ações;

t) preservar os recursos naturais do Município, especialmente suas matas, rios e cursos d água;

u) promover medidas judiciais e administrativas de responsabilização aos causadores de poluição ou de degradação ambiental;

v) garantir a existência de áreas verdes, no perímetro urbano, com a finalidade de garantir o lazer e a sadia qualidade de vida;

Além disso, o plano diretor do Município ${ }^{4}$, em seu artigo 111, prevê zonas de preservação ambiental, entre outras, mas também neste caso as políticas de execução de sua implementação são incipientes. O Plano Diretor é o instrumento básico para regularização da ocupação urbana, como bem destacado por

3 Disponível em: http://leismunicipais.com.br/leismunicipais/leiorganica/lages-sc/4624.html\&prefeitura=1. Acesso em: 12/mar/2012.

${ }^{4}$ http://www.lages.sc.gov.br/plano_diretor/lei_plano_diretor2007.pdf 
MAZZOLLI, M. Ocupação irregular em áreas de recarga do Aquífero ...

Ampessam Filho (2012). Um exemplo a ser seguido em termos de legislação é o de Ribeirão Preto, onde praticamente toda a água de abastecimento é oriunda do Aquífero Guarani. A partir de 1995 o Plano Diretor do município passou a exigir a destinação de um percentual maior das glebas urbanizada para a implantação de áreas verdes (35\% da área total), restrição de novos poços, e formação de um grupo de trabalho de zoneamento de áreas de afloramento do Aquífero, coordenado pelo Ministério Público, e estudo para criação de um geoparque (GOULART et al., 2012). No artigo 111 do Projeto de Lei Complementar $n^{\circ} 367 / 2006$ do município, condomínios urbanísticos horizontais de até $10 \mathrm{mil}$ metros quadrados devem manter uma área verde de $50 \%$ (Executivo Municipal, 2007). Mesmo com todas estas medidas preventivas, o lençol subterrâneo sofreu um rebaixamento de aproximadamente 60 metros na porção urbana, e a exploração hídrica atual é treze vezes superior à recarga da chuva (VILLAR e RIBEIRO, 2009).

Uma proposta para evitar o aumento da concentração urbana foi adotada no município de Gramado, situado na região nordeste do estado do Rio Grande do Sul. Promoveu-se o incentivo à construção de unidades e conjuntos residenciais populares nas áreas urbanas periféricas desocupadas, bem como em áreas do espaço rural. Assim como Lages, Gramado está inserido em uma região serrana, mas ao contrário de Lages, que aspira por tempos ser um pólo turístico, o município de Gramado sustenta sua economia no turismo, inclusive rural. Isto favorece o surgimento de empregos e a permanência e migração de famílias para o espaço rural, na contramão do êxodo rural experimentado no restante do Brasil (IBGE, 2010).

A ocupação irregular é algo generalizado no Brasil (JÚNIOR, 2003; ROCHA et al., 2006) e frequentemente requer a intervenção do Ministério Público através de Inquéritos Civis como uma ferramenta de intervenção, e nem sempre com sucesso em razão da dificuldade de remoção de moradias já instaladas (VARGAS et al., 2008). 
MAZZOLLI, M. Ocupação irregular em áreas de recarga do Aquífero ...

\section{Conclusões}

As formas de uso e ocupação no bairro Santa Helena foram identificadas (tipo de uso), espacializadas (mapa de uso) e quantificadas (percentual de área ocupada pelo tipo), demonstrando que o potencial risco de contaminação das águas subterrâneas e a supressão das áreas de preservação permanente apontam para a necessidade do desenvolvimento de estratégias de planejamento, sobretudo preventivas, que levem em consideração o uso e ocupação do solo. Embora previsto na Constituição Federal, faz-se necessário advertir que o controle do uso e ocupação do solo é de responsabilidade do Poder Público Municipal, que por meio das diretrizes estabelecidas em lei, deve gerenciar uma adequada ocupação do território garantindo o desenvolvimento urbano e o bem-estar dos habitantes. Desta forma, em última análise, este diagnóstico objetivou explicitar dados que possam ser utilizados no planejamento das ações públicas proporcionando uma ordenação na ocupação do solo, resultando em condições dignas de moradia e promoção da saúde e bem-estar da população e a conservação dos recursos naturais. A expansão da cidade deve ser pensada dentro das normas da legislação, e não seguindo processos de degradação natural como tem sido historicamente. É preciso uma política pública preventiva da ocupação, além de corrigir os danos causados, e principalmente criar políticas de remediação e coibir o crescimento a qualquer preço, muitas vezes promovido pelo próprio poder público municipal. O processo irregular de expansão estudado neste trabalho reflete não só a situação da área de estudo, mas é um processo generalizado, que precisa ser regularizado para garantir o desenvolvimento sustentável. 
MAZZOLLI, M. Ocupação irregular em áreas de recarga do Aquífero ...

\section{Referências bibliográficas}

ALMEIDA, F. R. de; ESPÍNDULA, J. C., Vasconcelos U.; Calazans, G. M. T. Avaliação da ocorrência de contaminação microbiológica no aquífero freático localizado sob o cemitério da várzea em Recife, PE. Águas Subterrâneas, v.20, n.2, p.19-26, 2006.

AMPESSAM FILHO, E. Necessidade de se efetivar a proteção dos aquíferos nas áreas de recarga e afloramentos nas cidades. In: Bravo, A. S. (ed.). Água \& Derechos Humanos. Sevilha (Espanha): ArCiBel Editores, p. 237-252, 2012.

ARRUDA, A. M. C. T. de; BARBOSA, M. G.; SILVA, J. DA, SILVA, T. C. DA; VASCONCELOS, M. C. DE; MORAES. M. F. D. Avaliação da qualidade microbiológica das águas subterrâneas em municípios da mesorregião do agreste Pernambuco, Brasil. In: XVI Congresso Brasileiro de Águas Subterrâneas e XVII Encontro Nacional de Perfuradores de Poços, 2010.

BARBOSA, R.I. Ocupação humana em Roraima. II. Uma revisão do equívoco da recente política de desenvolvimento e o crescimento desordenado. Bol. Mus. Par. Emílio Goeldi, v.9, n.2, p.177-197, 1993.

BORGHETTI, N. R. B.; BORGHETTI, J. R.; ROSA FILHO, E. F. da. Aqǘfero Guarani: a verdadeira integração dos países do Mercosul. Curitiba: Maxigráfica, 2004. 214p.

EXECUTIVO MUNICIPAL. 2007. Lei Complementar que dispões sobre o parcelamento, uso e ocupação do solo no município de Ribeirão Preto. Disponível em: http://www.ribeiraopreto.sp.gov.br/principaln.php?pagina=/leis/pes quisa/ver.php?id=21377. Acesso em: 06/dez/2012. 
MAZZOLLI, M. Ocupação irregular em áreas de recarga do Aquífero ...

GONÇALVES, C. S.; RHEINHEIMER, D. dos S.; PELLEGRINI, J. B. R.; KIRST, S. L. Qualidade da água numa microbacia hidrográfica de cabeceira situada em região produtora de fumo. Revista Brasileira de Engenharia Agrícola e Ambiental, v.9, n.3, p.391-399, 2005.

GOULART, M. P.; CAMPOS, H. C. N. S.; NEPOMUCENO, O. Tutela jurídica do Aquífero Guarani em Ribeirão Perto. Boletin Geológico y Minero, v.123, n.3, p.389-399, 2012.

IBGE. XII Levantamento demográfico, banco de dados SIDRA. Instituto Brasileiro de Geografia e Estatística, Rio de Janeiro. http://www.sidra.ibge.gov.br. Acesso em dezembro de 2011, 2010.

JÚNIOR, O. B. Interferência entre a ocupação urbana e a dinâmica no litoral sul do Paraná. Análise Conjuntural, v.25, n.11-12, p.13, 2003.

KOBIYAMA, M. Conceitos de zona ripária e seus aspectos geobiohidrológicos. In: Seminário de Hidrologia Florestal: Zonas Ripárias (1: 2003: Alfredo Wagner) Florianópolis: UFSC/PPGEA, Anais, 2003. p.1-13.

LIMA, C. de A.; MENDONÇA, F. Planejamento urbano-regional e crise ambiental: região metropolitana de Curitiba. São Paulo Perspec., São Paulo, v.15, n.1, 2001. Disponível em: http://www.scielo.br/scielo.php?script=sci_arttext\&pid=S0102$88392001000100015 \& \operatorname{lng}=\mathrm{en} \& \mathrm{nrm}=$ iso. Acesso em: 19/nov/2012.

POWELL, K. L.; TAYLOR, R. G.; CRONIN, A. A.; BARRETT, M. H.; PEDLEY, S.; SELLWOOD, J.; TROWSDALE, S. A.; LERNER, D. N. Microbial contamination of two urban sandstone aquifers in the UK. Water Res., v.37, n.2, p.339-352, 2003. 
MAZZOLLI, M. Ocupação irregular em áreas de recarga do Aquífero ...

ROCHA, L. C. R.; HORBE, A. M. C. Contaminação provocada por um depósito de lixo no aqüífero Alter do Chão em Manaus AM. Acta Amazônica, v.36, n.3, p.307-312, 2006.

SÁNCHEZ, P. S. O processo de ocupação em áreas de proteção aos mananciais: conflito com a lei e realidade social na Região Metropolitana de São Paulo. In: MARTINS, R. C.; VALENCIO, N. F. L. S (eds.). Uso e gestão dos recursos hídricos no Brasil. São Carlos: Rima, 2003. 293p.

SCHEIBE, L. F.; HIRATA, R. O contexto tectônico dos Sistemas Aqüíferos Guarani e Serra Geral em Santa Catarina: uma revisão. In: XV Congresso Brasileiro de Águas Subterrâneas, 2008, Natal, RN. Anais do XV Congresso Brasileiro de Águas Subterrâneas. Curitiba: Associação Brasileira de Águas Subterrâneas, 2008. v.único. p.01-14. 2008.

SDS. Panorama dos Recursos Hídricos de Santa Catarina. Secretaria de Estado de Desenvolvimento Sustentável. Florianópolis, maio 2006. 315p.

SECRETARIA DE ESTADO E DESENVOLVIMENTO URBANO E MEIO AMBIENTE. Diagnóstico Geral das Bacias Hidrográficas do Estado de Santa Catarina. Florianópolis $\mathrm{SC}$, 1997. Disponível em: http://www.aguas.sc.gov.br/sirhsc/biblioteca_visualizar_arquivos.j sp?idEmpresa=1\&idPasta=111. Acesso em: $\overline{19} / \mathrm{mar} / 2012$.

SEPLAN. Atlas de Santa Catarina. 2 ed. rev. e atual. Secretaria do Planejamento. Florianópolis: Letras Brasileiras, 2008, 96p.

SILVA, D. D.; PRUSKI, F. F.; SCHAEFER, C. E. G. R.; AMORIM, R. S. S.; PAIVA, K. W. N. Efeito da cobertura nas perdas de solo em um Argissolo Vermelho-Amarelo utilizando simulador de chuva. Engenharia Agrícola, v.25, n.2, p.409-419, 2005. 
MAZZOLLI, M. Ocupação irregular em áreas de recarga do Aquífero ... VANZELA, L. S.; HERNANDEZ, F. B. T.; FRANCO, R. A. M. Influência do uso e ocupação do solo nos recursos hídricos do Córrego Três Barras, Marinópolis. Revista Brasileira de Engenharia Agrícola e Ambiental, vol.14, n.1, p.55-64, 2010.

VARGAS, H. L. Ocupação irregular de APP urbana: um estudo da percepção social acerca do conflito de interesses que se estabelece na Lagoa do Prato Raso, em Feira de Santana, Bahia. Sitientibus n.39, p.7-37, 2008.

VILLAR, P. C.; RIBEIRO, W. C. Sociedade e gestão do risco: o aquífero Guarani em Ribeirão Preto-SP, Brasil. Revista de Geografia Norte Grande v.43, p.51-64, 2009.

WHITEHEAD, E.; HISCOCK, K.; DENNIS, P. Evidence for sewage contamination of the Sherwood Sandstone aquifer beneath Liverpool, UK. In: Ellis, J. B. (ed.). Impacts of urban growth on surface water and groundwater quality. Proceeding of the IUGG 99 Symposium HS5, Birminham, July 1999. Wallingford: International Association of Hydrological Sciences (IAHS) publ. $\mathrm{n}$ 259, 1999. 438p.

Recebido em dezembro de 2012 Aceito em maio de 2013 